\title{
Education programs for people living with chronic pain: a scoping review
}

Review

Hai-Ying Wang ${ }^{a}$, Carol Grech ${ }^{\mathrm{b}}$, David Evans ${ }^{\mathrm{b}}$, Rasika Jayasekara ${ }^{\mathrm{b}, *}$

aFamily Health Golden Grove, 205 The Golden Way, Golden Grove, South Australia 5125, Australia

${ }^{b}$ School of Nursing \& Midwifery, University of South Australia, Australia

Received: 7 March 2020; Accepted: 17 May 2020; Published: 20 December 2020

\begin{abstract}
Objective: The aim of this scoping review was to provide evidence for health practitioners to improve patient education practice for chronic pain management.

Methods: A scoping review was guided by Arksey and 0'Malley's (2005) five-stage framework, investigated contemporary patient education programs (2007-2018) for chronic pain management in education content, formats of delivery, and tools used for evaluation. Content analysis and description were used for the outcome report.

Results: Seven quantitative studies were included. Education content consisted of General information, Cognitive behavior therapy (CBT), Self-management, and Pain neurophysiology (PN). Education delivery formats varied from workbook to workbook, face-toface, online, when given for a group or individual or in a combined way. In total, 19 tools were reported for the evaluation of the education programs.

Conclusions: There is a variety in the education content and the delivery formats. The majority of programs showed effectiveness in patients' chronic pain management based on their selected evaluation tools. This review showed that patient education programs can be useful in chronic pain management. The effectiveness of patient education programs focuses on the improved patients' physical function and quality of life rather than the cessation of pain only.
\end{abstract}

Keywords: patient education $\bullet$ chronic pain management $\bullet$ scoping review $\bullet$ taxonomy $\bullet$ pain $\bullet$ patient education

(c) Shanxi Medical Periodical Press.

\section{Introduction}

Chronic pain is a prevalent and costly health care issue worldwide. ${ }^{2}$ The social and economic impact of individuals suffering from chronic pain is well documented in the literature. ${ }^{2-7}$ In Australia, one in five people is thought to live with chronic pain, and the prevalence rises to one in three among Australians aged $>65$ years. ${ }^{8}$ Chronic pain is often difficult and complex to treat and has become Australia's third most costly health problem. ${ }^{9,10}$

Current evidence suggests that chronic pain is managed effectively when a multidisciplinary health team is involved $d^{3,11-18}$ and a combination of therapeutic approaches is adopted including physiotherapy, psychological interventions, and medication. Patient education is an integral component of a successful pain management plan. ${ }^{13,19-22}$ People with chronic pain need

How to cite this article: Wang HY, Grech C, Evans D, et al. Education programs for people living with chronic pain: a scoping review. Front Nurs. 2020;4:307-320. 
to understand their condition, be active participants in their treatment, and comply with therapeutic interventions. ${ }^{23}$ Also, education is central in establishing and maintaining the positive behaviors needed for effectively managing the chronic pain. ${ }^{24}$

Practically, a multidisciplinary pain management program is evaluated as an all-inclusive intervention rather than as individual components. ${ }^{12,25,26}$ For example, patient education is not commonly evaluated as an integral component of a multidisciplinary program for people living with chronic pain for its standalone effectiveness. ${ }^{13,27}$ Questions related to the content, delivery mode, and timing of an effective chronic pain management education program remain largely unanswered. According to the British Pain Society, ${ }^{19}$ these factors should be evaluated appropriately.

To address this gap and better understand the current practice of patient education in chronic pain management, a scoping review was conducted. The aim of this review was to investigate contemporary education programs for chronic pain management, explore the education content, formats of delivery, and tools for evaluation, and identify the evidence of the best practice of patient education programs to inform health professionals about how these programs might be improved.

\section{Methods}

This scoping review was guided by Arksey and O'Malley's ${ }^{1}$ five-stage framework. A scoping review is defined as "a form of knowledge synthesis that addresses an exploratory research question aimed at mapping key concepts, types of evidence, and gaps in research related to a defined area or field by systematically searching, selecting, and synthesizing existing knowledge." ${ }^{28}$ Because of the nature of review, it answers a broad range of questions whereas the intention of a systematic review is to answer a well-defined question where there is an existing body of literature. ${ }^{29}$ Thus, a scoping review is different from a systematic review because it is exploratory, attempts to cover a broad field of literature, and can be undertaken to explore whether there is enough literature to inform a systematic review. In this case, the scoping review was designed to explore patient education practices for chronic pain management to identify best practice or knowledge gaps in this field. The five-stage framework involved: (1) identifying the research questions; (2) identifying relevant studies; (3) study selection; (4) data charting and collection; and (5) summarizing and reporting the results.

\subsection{Stage one: identifying the research questions}

The research questions posed for this review were:

(1) What is the content of the education programs for people living with chronic pain?

(2) How are these education programs delivered?

(3) What evaluation tools have been used to assess the effectiveness of the education programs for chronic pain management?

(4) What kinds of education programs are effective in chronic pain management?

\subsection{Stage two: identifying relevant studies}

To ensure that sufficient information was captured, a comprehensive database search was undertaken which included Medline, CINAHL, Embase, Health and Psychosocial Instruments, PsycINFO, Ovid Nursing Database, Health Collection, Ageline, Cochrane Library, and Scopus. Key search terms used were chronic pain, persistent pain, and patient education program. This review includes primary quantitative studies published in English between January 2007 and December 2018. This time frame was selected after considering the advancement of chronic pain management in Australia over this period. ${ }^{30}$ This review was limited to patient education programs only and studies that combine education with other interventions were excluded.

\subsection{Stage three: study selection}

In total, 1,146 articles were identified through the database search. After discarding the duplications, 514 articles remained. After title and/or abstract screening, 62 articles were identified to be relevant to the study questions. Full texts of these articles were obtained, with each article screened against the inclusion criteria. The inclusion criteria applied to selection were:

(1) primary research of a quantitative nature was reported;

(2) participants in the studies were $\geq 18$ years with non-cancer;

(3) chronic pain duration $\geq 3$ months and the education program was evaluated independently for its effectiveness.

Seven articles met the inclusion criteria. Examples of studies excluded were the articles in which there is no clear information on duration of pain of participants ${ }^{31,32}$; education was combined with other interventions ${ }^{33,34}$; and 
there is non-primary quantitative studies. ${ }^{35-37}$ The flowchart in Figure 1 shows the process of article selection.

\subsection{Stage four: data charting and collection}

Further, a data extraction form was developed and used for ensuring the accuracy of the data collected from selected studies. Data collected from studies included author(s), year of publication, the location (country) of study, study aims, study design, study setting, participants, outcomes, and a brief comment of the limitation. Details of the selected studies are provided in Table 1.

\subsection{Stage five: summarizing and reporting results}

In this stage, the extracted data were analyzed and then summarized. To address question 1 of the study (the content of education programs for people living with chronic pain), a content analysis was conducted to identify the key content or subject and that group key subject matter was covered in programs. To answer research questions $2-4$, information was extracted from the studies on the education delivery format; the evaluation tools were used to assess the effectiveness of the education program; the study outcomes; and reported descriptively.

\section{Results}

This review included 7 studies from 3 countries. Among these, 3 studies were conducted in USA, 3 in Belgium, and 1 in Australia. Four studies focused on the influences of different education contents. ${ }^{39-42}$ Two studies conducted only a pre to post test without using control groups for the evaluation of the effectiveness of the education programs, ${ }^{43,44}$ and one study focused on the influence of different delivery formats. ${ }^{38}$

\subsection{The content of the education programs for people living with chronic pain}

The content of education programs covered a broad range of information that was grouped into four categories: General information, CBT, Self-management, and PN (see Table 2 for the detail of the content of the education programs).

Data analysis showed that education programs for people living with chronic pain contained a range of general information which included information about symptom identification, ${ }^{38,44}$ treatment options and complementary treatment, ${ }^{39,40,43}$ pain medication, ${ }^{39,43,44}$ working with health professionals, ${ }^{38-40}$ eating and health, ${ }^{39,43}$ weight management and smoking cessation, ${ }^{43}$ and back pain causes, prevention, and treatments..$^{40}$ Five out of the

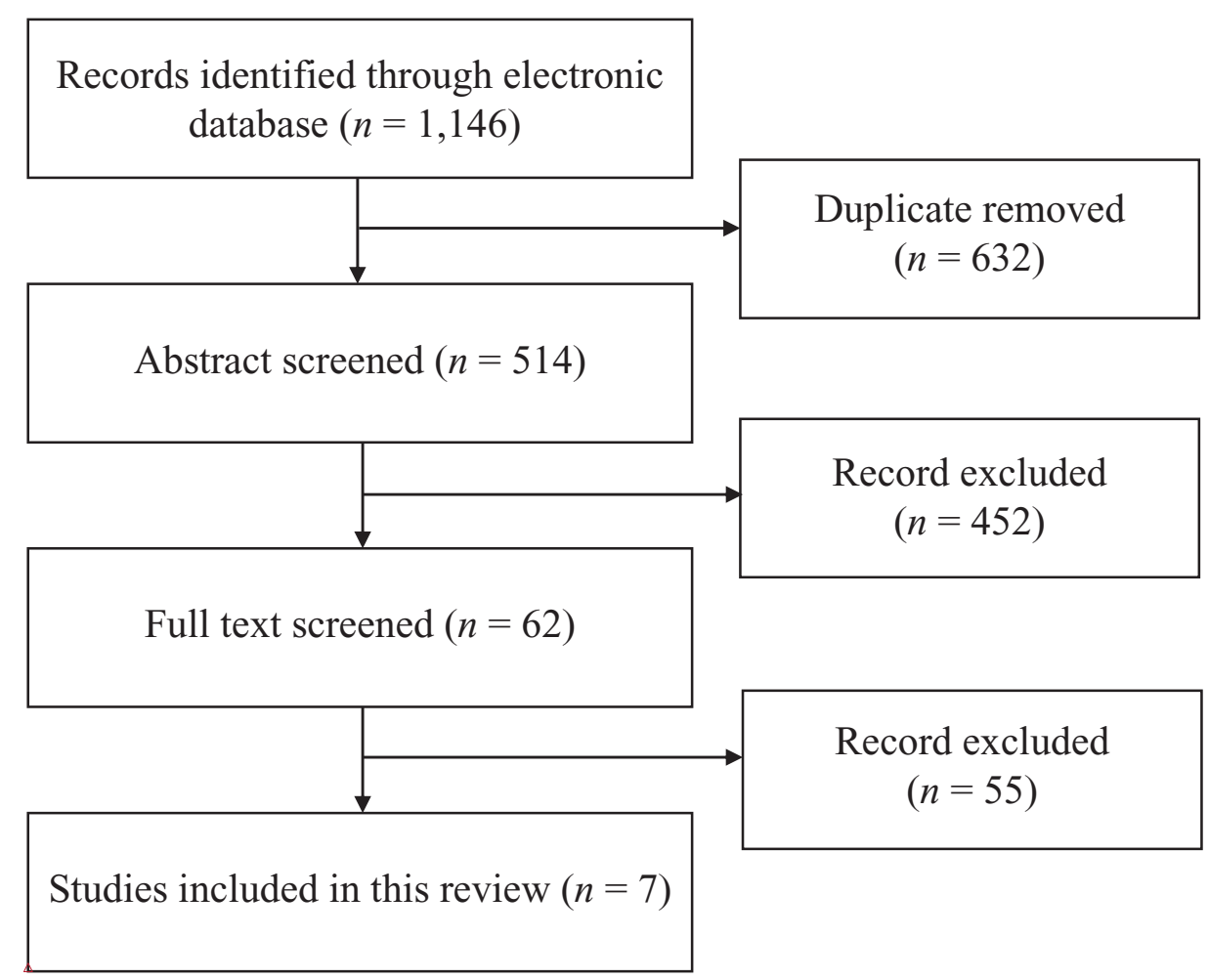

Figure 1. The review process flowchart. 


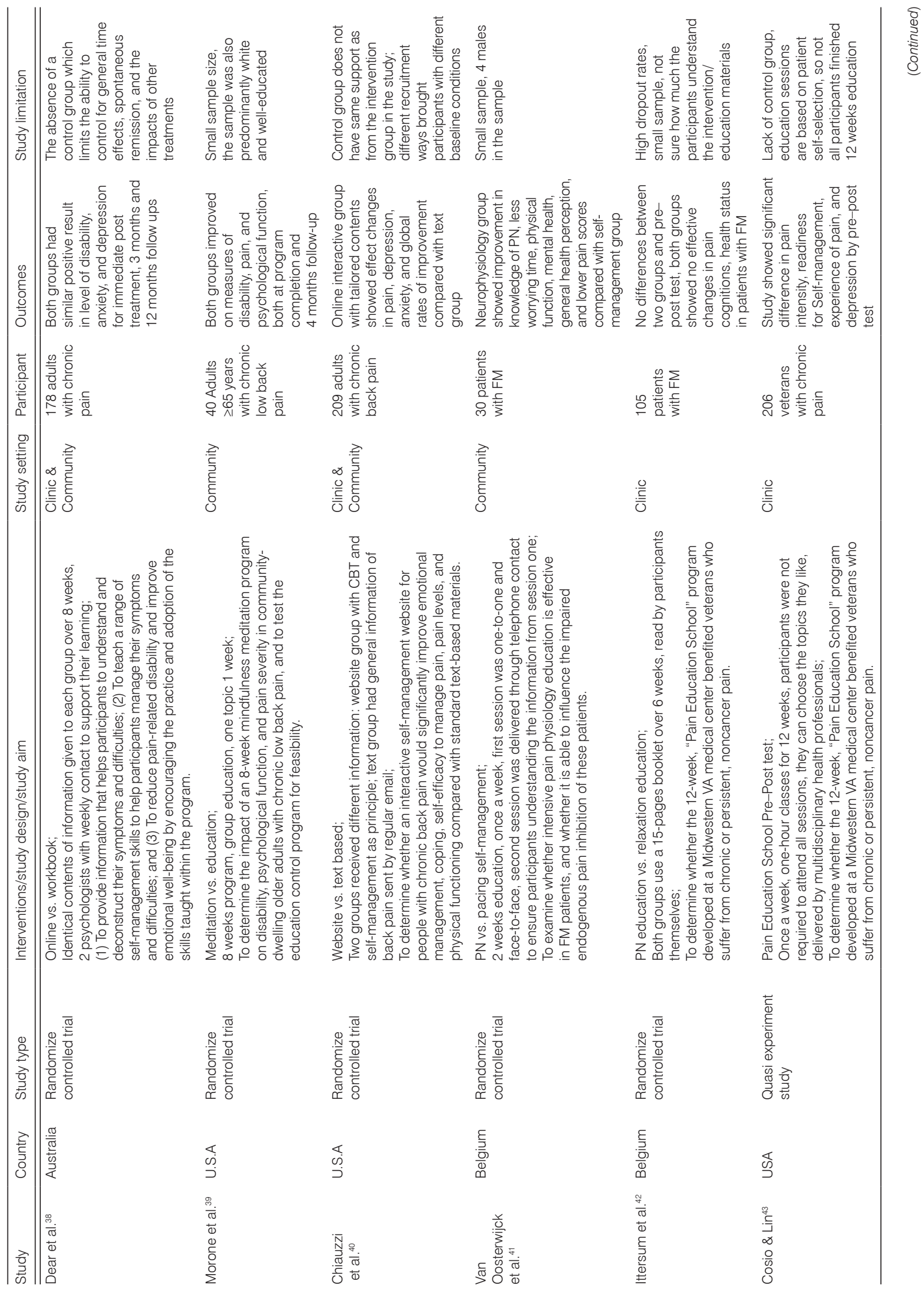


seven studies contained detailed information related to the above categories in their education programs, while one study has only information in regarding the above categories or features as its full education content. ${ }^{39}$

Data from this review showed CBT is a common focal point in patient education programs. Five studies included information about CBT in their patient education programs. ${ }^{38,40,42-44}$ However, each program had a different focus on the principle of CBT. This included thoughts and mood management, ${ }^{38,40,42}$ motivation enhancement, ${ }^{40,44}$ psychosocial factors on pain, ${ }^{43,44}$ self-efficacy, ${ }^{40,44}$ and pain acceptance and commitment therapy. ${ }^{43}$

Data of this review also indicated that Self-management is another common focal point for chronic pain management in patient education programs. Five studies encouraged people to learn skills of Self-management. The Self-management skills included relaxation, ${ }^{38,42,44}$ physical exercises, ${ }^{38,40,44}$ activity pacing, graded exposure and management strategies, ${ }^{38,44}$ goal setting, ${ }^{38,40,41}$ sleep management, ${ }^{38,40,43,44}$ stress management, ${ }^{38,40,42,44}$ relapse prevention, ${ }^{40,41}$ and structured problem solving. 38,40

According to the review, PN was not commonly included in the patient education programs when compared with other categories of information for chronic pain management. Two studies had a focus on the PN education. ${ }^{41,42}$ It provided a theory that nociceptive stimuli sent to the brain are not always reflected in pain experience, depending on persons' psychological state of mind and environment. The PN education provided information that tissue damage is necessary for a pain sensation but a pain sensation does not definitely mean tissue damage and the central nervous system has the ability to increase or decrease its sensitivity. In addition, it covers the information of differences between nociception and pain, acute pain and chronic pain, and further how acute pain becomes chronic. ${ }^{41,42}$ Also, the study of Ittersum and his colleagues, ${ }^{42}$ included information of central sensitization as part of PN education.

When we summarize the findings of this review, it showed that the majority of education programs used a combination of information in their educational content. Often the content covered information belonging to two to three categories (as identified above). For example, the education information in Cosio and Lin's study, ${ }^{43}$ mainly focused on General information and only briefly touched on CBT and PN. In general, General information, CBT, and Self-management were the most common content covered in current education programs. In addition, one study briefly reported the application of "healthy aging" as the part of education intervention for chronic pain management in which "brain health" was emphasized as the theme during the study period of time. ${ }^{39}$ 


\begin{tabular}{lccc}
\hline Study & \multicolumn{3}{c}{ Education contents } \\
\cline { 2 - 4 } & General information & CBT as principle & Self-management \\
\hline \hline Dear et al. ${ }^{38}$ & $\checkmark$ & $\checkmark$ & $\checkmark$ \\
Morone et al. ${ }^{39}$ & $\checkmark$ & & \\
Chiauzzi et al. ${ }^{40}$ & $\checkmark$ & $\checkmark$ & $\checkmark$ \\
Van Oosterwijck et al. ${ }^{41}$ & & $\checkmark$ & $\checkmark$ \\
Ittersum et al. ${ }^{42}$ & $\checkmark$ & $\checkmark$ & $\checkmark$ \\
Cosio \& Lin ${ }^{43}$ & $\checkmark$ & $\checkmark$ & \\
Morlion et al. ${ }^{44}$ & $\checkmark$ & $\checkmark$ & \\
\hline
\end{tabular}

Note: General information: symptoms identification, treatment options, complementary treatments, pain medications, working with health professionals, eating and health, weight management, smoking cessation; CBT as principle: thoughts and mood management, motivation enhancement, psychological factors on pain, self-efficacy, pain acceptance \& commitment therapy; Self-management: relaxation, physical exercise, activity pacing, graded exposure activity management strategy, goal setting, sleep management, stress management, relapse prevention, structured problem solving; PN: based on the book Explain Pain by Butler \& Moseley ${ }^{45}$ and theory of central sensitization that nociceptive stimuli sent to the brain are not always reflected in pain experience, depending on patient's psychological state of mind and environment. Difference between nociception and pain, Acute pain vs. chronic pain How acute pain becomes chronic, Potential sustaining factors of central sensitization.

CBT, Cognitive behavior therapy; PN, Pain neurophysiology.

Table 2. Education programs-contents.

\subsection{How are these education programs delivered?}

Varioius ways were identified in the delivery of patient education programs (Table 3). Workbooks/booklets and face-to-face teaching were the most common ways of delivery format used in patient education programs. Workbooks/booklets were used in four studies. Among them, two studies combined the booklet with online education ${ }^{38,40}$; One study combined the booklet with face-to-face group education, ${ }^{39}$ and one study used booklet as the only education medium. ${ }^{42}$ Three studies used face-to-face in group education sessions, ${ }^{39,43,44}$ and only one study used one-to-one and face-to-face delivery formats. ${ }^{41}$ Those delivering the patient education programs were from different health disciplines. Instructors involved are psychologists, ${ }^{38}$ physiotherapists, ${ }^{41,44}$ nurses, ${ }^{44}$ and other health professionals. ${ }^{39,43}$ Two studies did not have an education delivery instructor because the education was either in an online or in a booklet format. ${ }^{40,42}$

Different formats had been used in education delivery. Workbooks/booklets and face-to-face were the most commonly used education medium and almost $50 \%$ of the studies in this review used a combination of two ways in their education.

\subsection{What evaluation tools have been used to assess the effectiveness of the education programs for chronic pain management?}

There were 19 different measurement tools used for the evaluation of the education programs in selected studies (Table 4). The average number of the evaluation tools used in a study was 5 . The maximum number of tools used in one study ${ }^{40}$ was 8 and the minimum number of tools used was 3 in two studies. ${ }^{42,43}$ The most commonly used tool was the Pain Catastrophizing Scale, which was used in five studies. ${ }^{38,40-42,44}$

This scoping review found that the pain intensity was not the prime consideration in the evaluation of patient education programs. Regarding the chronic pain management, the studies had interest in the quality of life measurement, reflected by three studies using SF-36 Health Status Inventory. ${ }^{39,41,44}$ The confidence of patients moving with pain was the focus for evaluation of three studies using the Pain Self-Efficacy Questionnaire ${ }^{38-40}$ and four studies using the Kinesiophobia Scale to mea-

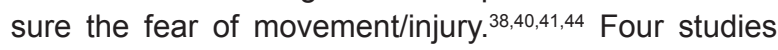
used questionnaires to evaluate the influence of patient education programs to improve participants' depression and anxiety. ${ }^{38,40,43,44}$ Patients' functional status was also evaluated by the Pain Disability Questionnaire, which was adopted in three studies. ${ }^{38,40,43,44}$ Further, participants' improvement in their knowledge of pain medication ${ }^{43}$; illness perception ${ }^{42}$; global impression of change ${ }^{40}$; mindfulness ${ }^{39}$; chronic pain acceptance ${ }^{38}$; knowledge of $\mathrm{PN}$, spatial summation procedures, pain vigilance and awareness ${ }^{41}$; and habitual action-proneness ${ }^{44}$ were also reported.

Selection of the evaluation tools used was influenced by and based on the study population and the education content. For example, the Fibromyalgia Impact Questionnaire was only used in the studies in which participants had fibromyalgia (FM). ${ }^{41,42}$ The Neurophysiology Knowledge Test questionnaire was only used in the study focusing on neurophysiology education. ${ }^{41}$ 


\begin{tabular}{|c|c|c|c|c|c|c|c|}
\hline \multirow[t]{2}{*}{ Study } & \multirow[t]{2}{*}{ Duration } & \multirow[t]{2}{*}{ Frequency } & \multirow[t]{2}{*}{ Delivered by } & \multicolumn{4}{|c|}{ Way of delivery } \\
\hline & & & & $\begin{array}{c}\text { Face- } \\
\text { to-Face } \\
\text { one-to-one }\end{array}$ & $\begin{array}{l}\text { Face- } \\
\text { to-Face } \\
\text { in group }\end{array}$ & Online & booklet \\
\hline Dear et al. ${ }^{38}$ & 8 weeks & $\begin{array}{l}7-10 \text { days } \times \text { a lesson, } \\
\text { for } 5 \text { lessons }\end{array}$ & $\begin{array}{l}\text { Psychologist } \times 2 \text { weekly } \\
\text { contact for learning } \\
\text { support }\end{array}$ & & & $\checkmark$ & $\checkmark$ \\
\hline Morone et al. ${ }^{39}$ & 8 weeks & $\begin{array}{l}1 \text { session } \times 90 \mathrm{~min} \text {, } \\
\text { once a week }\end{array}$ & $\begin{array}{l}\text { Health professional, not } \\
\text { specific }\end{array}$ & & $\checkmark$ & & $\checkmark$ \\
\hline Chiauzzi et al. ${ }^{40}$ & 4 weeks & $\begin{array}{l}\text { Website group: } 20 \mathrm{~min} \times \\
\text { twice a week } \\
\text { Text group: on their own } \\
\text { pace }\end{array}$ & $N / A$ & & & $\checkmark$ & \\
\hline Van Oosterwijck et al..$^{41}$ & 2 weeks & $\begin{array}{l}1 \text { session } \times 30 \mathrm{~min} \text {, } \\
\text { once a week }\end{array}$ & Physiotherapist & $\checkmark$ & & & $\checkmark$ \\
\hline Ittersum et al. ${ }^{42}$ & 6 weeks & $\begin{array}{l}\text { Read it several times with } \\
1 \text { or } 2 \text { days intermissions }\end{array}$ & $\mathrm{N} / \mathrm{A}$ & & & & $\checkmark$ \\
\hline Cosio \& Lin ${ }^{43}$ & 12 weeks & $\begin{array}{l}1 \text { session } \times 1 \mathrm{~h} \text {, once } \\
\text { a week }\end{array}$ & $\begin{array}{l}\text { Health professionals } \\
\text { from over } 20 \text { disciplines }\end{array}$ & & $\checkmark$ & & \\
\hline Morlion et al. ${ }^{44}$ & 2 weeks & $\begin{array}{l}2 \text { sessions } \times 2 \text { h per } \\
\text { week }\end{array}$ & $\begin{array}{l}\text { A physiotherapist, } \\
\text { A pain nurse, and a } \\
\text { clinical psychologist }\end{array}$ & & $\checkmark$ & & \\
\hline
\end{tabular}

Note: The duration of the education and the frequency for each session varied between the studies. The duration ranged from 2 weeks to 12 weeks. The frequency of the education sessions varied between twice a week ${ }^{40,44}$, once a week ${ }^{39,41,43}$, and 7-10 days for a session at the participants' pace of self-learning. ${ }^{38}$

Table 3. Education programs — way of delivery.

In summary, there was a broad range of tools used in the evaluation of the education programs. Though the focuses of the studies and the participant were different, the Pain Catastrophizing Scale was the most commonly used evaluation tool in this review.

\subsection{What kind of education programs are effective in chronic pain management?}

The majority of the studies ( 6 out of 7 ) reported that education programs are effective in chronic pain management. Although studies varied in education content, ways of delivery and the disciplinary background of instructors, the majority of the education programs reported positive outcomes in terms of reduction in participants' pain intensity, disability, anxiety, depression, and general health perception (Table 1). Studies that reported the most positive outcomes had information in all four categories (General information, CBT, Self-management, and PN). The study of Ittersum ${ }^{42}$ showed no difference between two education groups and the pre-post education outcomes, and it had a primary focus on $\mathrm{PN}$, and included some information on CBT and Self-management, but did not include General information. In Ittersum et al.'s study, ${ }^{42}$ a 15 -page booklet was given to participants so that they read the booklet themselves over 6 weeks with each participant being allowed to ask questions twice about the information they were given. The researchers of that study acknowledged that they were unsure whether the participants understood the information provided in the booklet and whether participants actually applied it to manage their chronic pain. Another study with same focus on $\mathrm{PN}^{41}$ did report positive outcomes in improved knowledge of PN, less worrying time, physical function, mental health, general health perception, and lower pain scores.

Three studies with positive outcomes used textbooks in their education programs. However, they all had health professionals' support or direct contact with an instructor during their education sessions. Education content and the way it is delivered appear to be factors in the success of a patient education programs.

The studies selected in this review used different evaluation tools, and the lack of consistency in the tools makes the comparison of education programs a challenging task. The most common tool was the Pain Catastrophizing Scale, which was used in 5 studies. Dear and colleagues' studied ${ }^{38}$ the most effective patient education program based on this tool, in which they compared the outcomes of different delivery ways of the same education contents through the online and workbook formats. The education content in this study included the General information, CBT, and Self-management, and the program conducted over 8 weeks for 5 lessons with two psychologists' having weekly contact with the participants to support their learning. ${ }^{38}$ Findings of this scoping review suggest that 


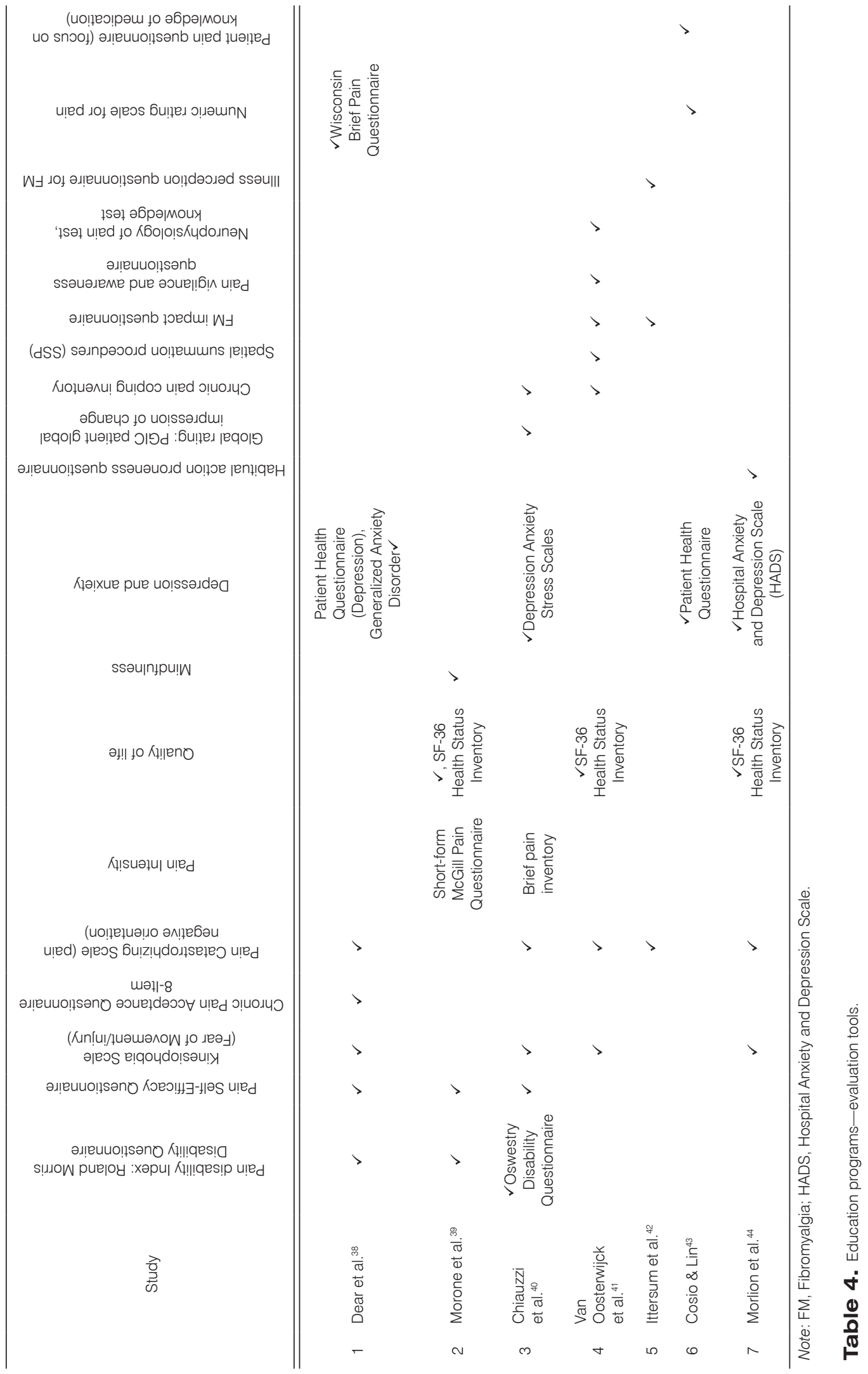


patient education programs can be effective, but the current evidence is inconclusive related to the specific characteristics comprising the best practice, and further research is needed.

In general, most studies reported positive outcomes based on their selected evaluation tools. The effectiveness of chronic pain management seems to be the improved quality of life, not merely focusing on the reduction of pain.

\section{Discussion}

Overall, there is a dearth of studies that investigate the impact of education programs for people living with chronic pain. The majority of articles identified in this scoping review were related to multidisciplinary pain management programs and therapeutic interventions. Although patient education is important in chronic pain management, the evaluation of its impact on people with chronic pain is not well studied.

This review has identified that the education content of programs designed to support people living with chronic pain primarily falls into four categories. Category one, the General information, provided the explanation of chronic pain, treatment options, and healthy lifestyle. It is observed that even this simple information was found helpful for people living with chronic pain. In this review, five studies contributed information to this category, and they all reported positive outcomes. ${ }^{38-40,43,44}$ It appears that this category of information is needed by people living with chronic pain and could be considered for inpatient education programs in chronic pain management.

Category two, CBT, has been recommended as an effective therapy for chronic pain management, ${ }^{46-48}$ and it has been adopted in a number of multidisciplinary chronic pain management programs. ${ }^{13,21,22,49-52}$ This scoping review found that CBT was used in the majority of the patient education programs. These studies suggested CBT may reduce pain intensity and painrelated distress, anxiety, and improve physical function by decreasing maladaptive thoughts and behaviors to increase self-efficacy skills in their pain management. ${ }^{53}$ However, treatment gains of CBT have been found to be short term ${ }^{54-56}$ and there is a need for long-term effective interventions.

Category three, Self-management is highly recommended in the literature for managing chronic health conditions ${ }^{57}$ including chronic pain management where it has been found to have some success. ${ }^{58-60}$ This review supported other research ${ }^{61}$ which found that Self-management emphasizes the individual's active role in their pain management and is strongly advocated as a major component in current chronic pain management programs. ${ }^{61}$ Selfmanagement prepares and empowers people with chronic pain to take an active role to manage their health over passive reliance on health professionalled care. ${ }^{62}$ To equip people with the knowledge and skills of direct care, education can be used as an effective and economical intervention. However, while Self-management is a popular component in the chronic pain management programs the person's readiness to self-manage needs to be assessed for a successful outcome. ${ }^{63}$

Category four, PN education, is relatively new for education, but an important area in chronic pain management. PN education is given alternative names such as therapeutic neuroscience education, pain biology education, and pain neuroscience education in various programs. ${ }^{64}$ Here, two studies had contradictory findings regarding the effectiveness of the PN education to people with chronic pain. Both studies were conducted in Belgium with a targeted population of FM and their education programs were based on the theory of a book by Butler \& Moseley ${ }^{45}$ titled Explain Pain. One study showed positive outcomes ${ }^{41}$ whereas the other did not. ${ }^{42}$ This may have been explained by the delivery mode-positive outcomes reported when the instruction was given by face-to-face, one-to-one teaching, and additional telephone follow-up to make sure that all participants understood the information they were given. ${ }^{41}$ Conversely, the study that used a booklet as the only way to deliver the education (inclusive of two opportunities to ask questions pertaining to the information participants were given) was found to be ineffective. ${ }^{42}$ Understanding PN can be challenging for people with chronic pain who might lack the capacity to understand its complexity. ${ }^{65}$ Health professionals can also find $\mathrm{PN}$ challenging to teach because the concept is commonly confused with CBT and gate control theory. ${ }^{64}$ But there is conclusive evidence that appropriate PN education can reduce chronic pain. ${ }^{66-69}$ Most studies have the small sample size, and so larger and more pragmatic clinical trials are needed.

Regarding the education delivery format to patient, website-based education may result in some potential outcome in chronic pain management. This review showed that the delivery formats of the education programs does not likely to affect the educational outcomes as most programs with different delivery formats had positive outcomes. Chronic pain is prevalent and has a significant impact on healthcare resources. The long waiting list and the expensive cost are the problems faced by healthcare organizations..$^{30}$ People who attend a pain management program have a pain history of nearly 10 years. $^{70}$ So, an effective and easily delivered 
intervention program is urgently required for this population. The internet-based chronic pain education programs had its advantages. With the widespread use of the internet and smartphones, people with chronic pain can easily access the education online. Compared with the traditional face-to-face classes, online education has a low cost for both the patient and the health organizations. ${ }^{71,72}$ The flexibility of online education benefits those who are physically unable to attend the face-toface classes due to the illness, family commitment, or other reasons. It provides the equal opportunity to vulnerable section of the people to access the pain management services.

A variety of evaluation tools are used to measure the effectiveness of education programs. People in the community with chronic pain seek pain management programs with expectation that they will benefit from participation. However, in reality, not all participants will benefit, and not all positive benefits will be sustainable. This is reflected in a shift from focusing on measuring pain relief to evaluating improved quality of life despite pain. Of the 19 evaluation tools identified during this review, only two measured pain intensity using shortform McGill Pain Questionnaire and brief pain inventory (Morone et al. ${ }^{39}$; Chiauzzi et al. ${ }^{40}$ ). Current practice seems to equate effectiveness of pain management programs to the improvement of participants' physical function and quality of life and a positive outcome is not just about the cessation of pain.

Contemporary chronic pain management programs encourage participants to take an active role in managing their condition. Those with chronic pain who are focused on pain relief outcomes are more likely to be passive recipients of care and rely on health professionals to manage their pain. This suggests that a successful pain management program needs to screen participants to assess whether they need additional education regarding expectations and Self-management.

A biopsychosocial model is commonly used to manage chronic pain, so the evaluation of the intervention in such model should consider all the changes from bio, psycho, and social aspects. Therefore, both the

\section{References}

1. Arksey H, O’Malley L. Scoping studies: towards a methodological framework. Int J Soc Res Methodol. 2005;8:19-32.

2. Gatchel RJ, Okifuji A. Evidence-based scientific data documenting the treatment and cost-effectiveness of comprehensive pain programs for chronic nonmalignant pain. J Pain. 2006;7:779-793. subjective and objective measurements should be considered in the evaluation. ${ }^{27,73}$ Pain is a subjective experience, so it is unclear whether objective measurements can really reflect the subjective experience of pain.

The variety of the evaluation tools used in studies indicates that there is a lack of simple and effective standardized tools for the evaluation of the education programs in chronic pain management. ${ }^{74,75}$ In this review, three studies used SF-36 health status inventory as the assessment tool for evaluation of the quality of life. ${ }^{39,41,44}$ However, SF-36 may not be sensitive enough to measure the quality of life for people with chronic pain. ${ }^{76}$ There is an urgent need to clarify what is meant by effective in chronic pain management and what tools should be used in the evaluation of the interventions for chronic pain management. Without standardized evaluation tools, positive outcomes do not guarantee the effectiveness of the interventions in chronic pain management.

\section{Conclusions}

Findings of this scoping review suggest that patient education programs can be effective, but the current evidence is inconclusive regarding to what features comprises best practice in the content, delivery mode, and timing (length and follow-up) of programs. Further research is needed using standardized evaluation tools to identify best practice models and recognize the shift from focusing on measuring pain relief to evaluating the improved quality of life for those living with chronic pain.

This review provided useful information for health practitioners to consider improving patient education programs for chronic pain management. Further research areas for chronic pain management were also indicated.

\section{Ethical approval}

Ethical issues are not involved in this paper.

\section{Conflicts of interest}

All contributing authors declare no conflicts of interest.
3. Pergolizzi J, Ahlbeck K, Aldington D, et al. The development of chronic pain: physiological CHANGE necessitates a multidisciplinary approach to treatment. Curr Med Res Opin. 2013;29:1127-1135.

4. Toth C, Lander J, Wiebe S. The prevalence and impact of chronic pain with neuropathic pain 
symptoms in the general population. Pain Med. 2009;10:918-929.

5. Reid KJ, Harker J, Bala MM, et al. Epidemiology of chronic non-cancer pain in Europe: narrative review of prevalence, pain treatments and pain impact. Curr Med Res Opin. 2011;27:449-462.

6. Flor H, Turk DC, Scholz OB. Impact of chronic pain on the spouse: marital, emotional and physical consequences. J Psychosom Res. 1987;31:63-71.

7. Kemler MA, Furnée CA. The impact of chronic pain on life in the household. J Pain Symptom Manage. 2002;23:433-441.

8. Painaustralia. Painful Facts. 2011. https://www. painaustralia.org.au/about-pain/painful-facts. Accessed December 12, 2019.

9. Australian Bureau of Statistics. Characteristics of bodily pain in Australia; 2011. https://www.abs.gov.au/ausstats/abs@.nsf/ Lookup/4841.0Chapter12011. Accessed December 12, 2019.

10. Australian Institute of Health and Welfare. Characteristics of bodily pain in Australia. 2016. Cat.no. 4841.0.

11. Guzmán J, Esmail R, Karjalainen K, et al. Multidisciplinary biopsychosocial rehabilitation for chronic low back pain. The Cochrane Database of Systematic Reviews. 2002;1:CD000963.

12. Deutsch A, LeMarchand K, Tameem A. Multi-disciplinary pain management programme (PMP). British J Pain. 2017;11(2 suppl 1):55-56.

13. Gunreben-Stempfle B, Griessinger N, Lang E, Muehlhans B, Sittl R, Ulrich K. Effectiveness of an intensive multidisciplinary headache treatment program. Headache. 2009;49:990-1000.

14. Marin TJ, Van Eerd D, Irvin E, et al. Multidisciplinary biopsychosocial rehabilitation for subacute low back pain. Cochrane Database Syst Rev. 2017;6:CD002193.

15. American Chronic Pain Association. ACPA Resource Guide to Chronic Pain Management, an Integrated Guide to Medical, Interventional, Behavioural, Pharmacologic and Rehabilitation Therapies. Rocklin, CA: American Chronic Pain Association; 2017.

16. Pieber K, Herceg M, Quittan M, Csapo R, Müller $\mathrm{R}$, Wiesinger GF. Long-term effects of an outpatient rehabilitation program in patients with chronic recurrent low back pain. Eur Spine J. 2014;23:779-785.

17. Heigl F, Schärer P, Widmer Leu C, et al. AB1247HPR Interprofessional bio-psycho-social rehabilitation and its effects on suffering and occupational performance-an observational study of a cohort of 92 chronic pain patients. Ann Rheum Dis. 2015;74:1351-1352.
18. Dysvik E, Kvaløy JT, Natvig GK. The effectiveness of an improved multidisciplinary pain management programme: a 6- and 12-month follow-up study. J Adv Nurs. 2012;68:1061-1072.

19. The British Pain Society. Guidelines for Pain Management Programmes for adults An evidencebased review prepared on behalf of the British Pain Society. London: The British Pain Society; 2013.

20. MAYO Clinic. Comprehensive Pain Rehabilitation Center Program Guide; 2006.

21. Heutink M, Post MWM, Bongers-Janssen HM, et al. The CONECSI trial: results of a randomized controlled trial of a multidisciplinary cognitive behavioral program for coping with chronic neuropathic pain after spinal cord injury. Pain. 2012;153:120-128.

22. Boschen KA. A multidisciplinary CBT pain management group program: outcomes for patients with chronic non-cancer pain. Arch Phys Med Rehabil. 2012;93:E52-E53.

23. Van Huet H, Innes E, Stancliffe R. Occupational therapists perspectives of factors influencing chronic pain management. Aust Occup Ther J. 2013;60:56-65.

24. Meeus M, Nijs J, Van Oosterwijck J, Van Alsenoy V, Truijen S. Pain physiology education improves pain beliefs in patients with chronic fatigue syndrome compared with pacing and self-management education: a double-blind randomized controlled trial. Arch Phys Med Rehabil. 2010;91:1153-1159.

25. Aragonès $E$, López-Cortacans $G$, Caballero A, et al. Evaluation of a multicomponent programme for the management of musculoskeletal pain and depression in primary care: a cluster-randomised clinical trial (the DROP study). BMC Psychiatry. 2016;16:69.

26. Carbonell-Baeza A, Aparicio VA, Ortega FB, et al. Does a 3-month multidisciplinary intervention improve pain, body composition and physical fitness in women with fibromyalgia? Br J Sports Med. 2011;45:1189-1195.

27. Reddy A, Oken JE, Schwarz L, Ruroede K. Evaluation of comprehensive pain management program with utilization of a functional assessment tool. PM \& R. 2013;5:S285-S286.

28. Colquhoun HL, Levac D, O'Brien KK, et al. Scoping reviews: time for clarity in definition, methods, and reporting. J Clin Epidemiol. 2014;67:1291-1294.

29. O'Connor D, Green S, Higgins JE.. Cochrane Handbook for Systematic Reviews of Interventions: Cochrane Book Series. Defining the review question and developing criteria for including studies; 2008.

30. National Pain Summit Initiative. National Pain Strategy Pain Management for all Australians; 2010. 
31. Horvat B, Jamnik H. Importance of an education programme for patients with chronic widespread pain. Int J Rehabil Res. 2016;39:361-364.

32. Watson EC, Cosio D, Lin EH. Mixed-method approach to veteran satisfaction with pain education. J Rehabil Res Dev. 2014;51:503-514.

33. Salvetti Mde G, Cobelo A, Vernalha Pde M, Vianna C, Ide A, Canarezi LCCCC, Calegare RGL. Effects of a psychoeducational program for chronic pain management. Rev Lat Am Enfermagem. 2012;20:896-902 (in English, Portuguese, Spanish).

34. Sorensen PH, Bendix T, Manniche C, Korsholm L, Lemvigh D, Indahl A. An educational approach based on a non-injury model compared with individual symptom-based physical training in chronic LBP. A pragmatic, randomised trial with a one-year followup. BMC Musculoskelet Disord. 2010;11:212.

35. May S. Self-management of chronic low back pain and osteoarthritis. Nat Rev Rheumatol. 2010;6:199-209.

36. Nijs J, van Wilgen CP, Van Oosterwijck J, van Ittersum M, Meeus M. How to explain central sensitization to patients with 'unexplained' chronic musculoskeletal pain: practice guidelines. Man Ther. 2011;16:413-418.

37. Rod K. Finding ways to lift barriers to care for chronic pain patients: outcomes of using internet-based self-management activities to reduce pain and improve quality of life. Pain Res Manag. 2016;2016:8714785.

38. Dear BF, Gandy M, Karin E, et al. The pain course: a randomised controlled trial comparing a remotedelivered chronic pain management program when provided in online and workbook formats. Pain. 2017;158:1289-1301.

39. Morone NE, Rollman BL, Moore CG, Li Q, Weiner DK. A mind-body program for older adults with chronic low back pain: results of a pilot study. Pain Med. 2009;10:1395-1407.

40. Chiauzzi E, Pujol LA, Wood M, et al. PainACTION-back pain: a self-management website for people with chronic back pain. Pain Med. 2010;11:1044-1058.

41. Van Oosterwijck J, Meeus M, Paul L, et al. Pain physiology education improves health status and endogenous pain inhibition in fibromyalgia a double-blind randomized controlled trial. Clin J Pain. 2013;29:873-882.

42. Ittersum $M$, et al. Does pain physiology education change illness perceptions in patients with fibromyalgia? A randomised controlled trial with six months follow up [abstract]. Physiotherapy (United Kingdom). 2011;97 Supplement 1:eS1291.
43. Cosio D, Lin EH. Effects of a pain education program for veterans with chronic, noncancer pain: a pilot study. J Pain Palliat Care Pharmacother. 2013;27:340-349.

44. Morlion B, Kempke S, Luyten P, Coppens E, Van Wambeke P. Multidisciplinary pain education program (MPEP) for chronic pain patients: preliminary evidence for effectiveness and mechanisms of change. Curr Med Res Opin. 2011;27: 1595-1601

45. Butler DS, Moseley GL. Explain Pain. Adelaide, Australia: Noigroup Publications; 2003.

46. Boschen KA, Robinson E, Campbell KA, et al. Results from 10 years of a CBT pain self-management outpatient program for complex chronic conditions. Pain Res Manag. 2016;2016:4678083.

47. Tsiliakou $\mathrm{N}$, et al. Cognitive behavioral therapy (CBT) in Greek patients with inflammatory arthritis: preliminary results. Rheumatology. 2012;51:i24.

48. Morley S. Efficacy and effectiveness of congnitive behaviour therapy for chronic pain: progress and some challenges. Pain. 2011;152(3 suppl):S99-S106.

49. Dysvik E, Kvaløy JT, Stokkeland R, Natvig GK. The effectiveness of a multidisciplinary pain management programme managing chronic pain on pain perceptions, health-related quality of life and stages of change-a non-randomized controlled study. Int J Nurs Stud. 2010;47:826-835.

50. Gaul C, Liesering-Latta E, Schäfer B, Fritsche G, Holle D. Integrated multidisciplinary care of headache disorders: a narrative review. Cephalalgia. 2016;36:1181-1191.

51. Bath AK, Gota CE, Cavolo AM, Davin S. Immediate benefits of a multidisciplinary educational program for fibromyalgia on patients' pain related self-efficacy and health locus of control [abstract]. Arthritis Rheumatol. 2015;67(suppl 10). https://acrabstracts. org/abstract/immediate-benefits-of-a-multidisciplinary-educational-program-for-fibromyalgia-onpatients-pain-related-self-efficacy-and-health-locusof-control/. Accessed January 5, 2020.

52. Stein KF, Miclescu A. Effectiveness of multidisciplinary rehabilitation treatment for patients with chronic pain in a primary health care unit. Scand $J$ Pain. 2013;4:190-197.

53. Ehde DM, Dillworth TM, Turner JA. Cognitivebehavioral therapy for individuals with chronic pain Am Psychol. 2014;69:153-166.

54. Burns JW, Nielson WR, Jensen MP, Heapy A Czlapinski R, Kerns RD. Specific and general therapeutic mechanisms in cognitive behavioral treatment of chronic Pain. J Consult Clin Psychol. 2015;83:1-11. 
55. Eccleston C, Willians A, Morley S. Psychological therapies for the management of chronic pain (excluding headache) in adults. Cochrane Database Syst Rev. 2009;2:CD007407.

56. Willians A, Eccleston C, Morley S. Psychological therapies for the management of chronic pain (excluding headache) in adults. Cochrane Database Syst Rev. 2012;11:CD007407.

57. Lu Y, Li Z, Arthur D. Mapping publication status and exploring hotspots in a research field: chronic disease self-management. $J$ Adv Nurs. 2014;70:1837-1844.

58. Nicholas MK, Asghari A, Blyth FM, et al. Selfmanagement intervention for chronic pain in older adults: a randomised controlled trial. Pain. 2013;154:824-835.

59. Richardson J, Loyola-Sanchez A, Sinclair S, et al. Self-management interventions for chronic disease: a systematic scoping review. Clin Rehabil. 2014;28:1067-1077.

60. Joshi $P$, Ochs L, Ito K, et al. Pain self-management interventions that are effective and practical in rural settings: results from a systematic literature review. J Pain. 2014;1:S11.

61. Kawi J. Self-management and support in chronic pain subgroups: integrative review. J Nurse Pract. 2013;9:110.e5-115.e5.

62. Barlow J, Wright C, Sheasby J, Turner A, Hainsworth J. Self-management approaches for people with chronic conditions: a review. Patient Educ Couns. 2002;48:177-187.

63. Mann EG, LeFort S, VanDenKerkhof EG. Selfmanagement interventions for chronic pain. Pain Manag. 2013;3:211-222.

64. Mosley GL, Butler DS. Fifteen years of explaining pain: the past, present, and future. J Pain. 2015;16:807-813.

65. Moseley L. Unraveling the barriers to reconceptualization of the problem in chronic pain: the actual and perceived ability of patients and health professionals to understand the neurophysiology. J Pain. 2003;4:184-189.

66. Pires D, Cruz EB, Caeiro C. Aquatic exercise and pain neurophysiology education versus aquatic exercise alone for patients with chronic low back pain: a randomized controlled trial. Clin Rehabil. 2015;29:538-547.
67. Goldberg C. Short-term effects of pain neurophysiology education and a multi-modal graded exercise program for a patient with chronic low back pain and prior lumbar fusion. J Manual Manipulative Ther. 2010;18:224-225.

68. Mosley GL. Evidence for a direct relationship between cognitive and physical change during an education intervention in people with chronic low back pain. Eur J Pain. 2004;8:39-45.

69. Van Oosterwijck J, Nijs J, Meeus M, et al. Pain neurophysiology education improves cognitions, pain thresholds and movement performance in people with chronic whiplash: a pilot study. J Rehabil Res Dev. 2011;48:43-58.

70. Mehlsen M, et al. Stanford Chronic Pain SelfManagement Programme (CPSMP): effects on pain catastrophizing, functional limitations, and benefit finding. J Psycho Res. 2011;70:606-607.

71. Schweier R, Romppel M, Richter C, Grande G. Dissemination strategies and adherence predictors for web-based interventions - how efficient are patient education sessions and email reminders? Health Educ Res. 2016;31:384-394.

72. Perry J, VanDenKerkhof EG, Wilson R, Tripp DA. Guided internet-based psycho-educational intervention using cognitive behavioral therapy and self-management for individuals with chronic pain: a feasibility study. Pain Manag Nurs. 2017;18:179-189.

73. Block C, et al. Improvements in objective and subjective functioning following completion of an interdisciplinary pain rehabilitation program. $J$ Pain. 2011;1:P85.

74. Gerdle B, Molander P, Stenberg G, Stålnacke BM, Enthoven $P$. Weak outcome predictors of multimodal rehabilitation at one-year follow-up in patients with chronic pain - a practice based evidence study from two SQRP centres. BMC Musculoskelet Disord. 2016;17:490.

75. Kowal J, Willson KG, Corace K, Henderson P. Patient and clinician global ratings of change following interdisciplinary treatment for chronic pain. J Pain Manag. 2010;3:161-170.

76. Matei $D$, et al. Management of chronic pain in osteoarthritis of the knee patients. Osteoporosis Int. 2013;1:S189. 